\title{
Optimum serum glucose levels for patients with severe traumatic brain injury Donald W Marion ${ }^{1,2}$
}

\author{
Address: ${ }^{1}$ Department of Neurosurgery, University of New Mexico School of Medicine, Albuquerque, NM 87131-0001, USA; ${ }^{2} 35$ High Rock \\ Road, Wayland, MA 01778, USA \\ Email: donmarion1@yahoo.com
}

FI000 Medicine Reports 2009, I:42 (doi:I0.34I0/MI-42)

The electronic version of this article is the complete one and can be found at: http://F/000.com/Reports/Medicine/content/l/42

\begin{abstract}
Tight glucose control during the acute care of patients with severe traumatic brain injury has recently been advocated based on experimental concerns about deleterious effects of presenting the injured brain with a high glucose load, however, there is little or no clinical evidence that hyperglycemia worsens neurologic injury. The majority of the clinical studies of tight glucose control find that it is associated with an increased risk of hypoglycemic episodes and cellular injury, when compared to conventional glucose control protocols.
\end{abstract}

\section{Introduction and context}

Traumatic brain injury (TBI) causes cerebral ischemia and disrupts normal cerebral metabolism. Anaerobic conditions result in post-traumatic changes in glucose metabolism that can have long-term consequences. For example, in chronic TBI studies, 6 months after patients suffered diffuse axonal injury, fluorodeoxyglucose positron emission tomography (PET) analysis shows bilateral regional decreases of resting glucose metabolism in the frontal and temporal lobes, thalamus, and cerebellum, compared with healthy gender-matched controls [1]. In patients with persistent neuropsychological deficits, these glucose hypometabolic areas are especially prominent in the cingulate gyrus [2].

Early after TBI, elevated serum glucose levels have been considered deleterious based on the assumption that presentation of the ischemic brain with high levels of glucose would drive anaerobic glycolysis, resulting in the accumulation of toxic levels of lactic acid. At least one study found that persistent hyperglycemia, defined as average daily blood glucose levels $>149 \mathrm{mg} / \mathrm{dl}$ for the first week after injury, was associated with a five-fold increase in mortality in a cohort of 834 patients with severe TBI [3]. Others have found that maintenance of blood glucose below $145 \mathrm{mg} / \mathrm{dl}$ significantly reduces lactate production, and results in optimal lactate/glucose and oxygen/glucose indices (as determined from arterialjugular venous lactate, and glucose and oxygen content differences) following severe TBI, at least as compared to higher blood glucose levels [4].

The mechanisms whereby glucose may worsen the ischemic threshold in neurons after injury are not well understood. In neuron cultures exposed to ischemic conditions, post-ischemic superoxide production and cell death are prevented by removing glucose from the medium [5]. These studies suggest that glucose is a requisite electron donor for reperfusion-induced neuronal superoxide production. Moreover, investigations of the mechanisms of neuronal injury that result from hypoglycemic coma have led some to conclude that the injury from hypoglycemia actually occurs with reperfusion, where high blood glucose concentrations initiate neuronal death by a mechanism involving extracellular zinc release and activation of neuronal NADPH oxidase [6]. Because of the depression of aerobic metabolism following TBI, and associated mitochondrial dysfunction, elevation of brain tissue $\mathrm{O}_{2}$ tension has been shown to significantly reduce extracellular lactate concentrations 
and the lactate/pyruvate ratio [7]. There is both clinical and experimental evidence that hyperglycemia lowers the ischemic neuronal threshold in the presence of neurological injury, and that lactic acidosis increases astrocytic cell death [8-10]. However, large clinical trials of therapies designed to induce a metabolic alkalosis [tromethamine (THAM)] or respiratory alkalosis (hyperventilation), based on the concern about post-traumatic lactic acidosis, did not find outcomes to be improved with these therapies $[11,12]$. In fact, there was some evidence that outcomes were actually worse when patients received prophylactic hyperventilation therapy.

\section{Recent advances}

\section{Tight glucose control}

Based on the concern that even slightly elevated blood glucose levels can cause or exacerbate secondary brain injury, investigators have conducted clinical trials to test the efficacy of 'tight glucose control', or maintenance of blood glucose levels of less than $110-120 \mathrm{mg} / \mathrm{dl}$ by using continuous insulin infusions. In a prospective study of 240 adult patients with severe TBI, patients were randomly assigned either to a tight glucose control group (intensive insulin therapy) with glucose levels maintained at $80 \mathrm{mg} / \mathrm{dl}$ throughout their intensive care unit (ICU) stay, or to a conventional glucose control group where insulin was not given unless serum glucose levels exceeded $200 \mathrm{mg} / \mathrm{dl}$ [13]. The groups were well matched according to several measures of severity of injury and age. Six-month mortality rates were similar for the two groups, though significantly more patients in the intensive insulin therapy group had good outcomes (that is, a Glasgow Outcome Scale (GOS) score of 4 or 5) than did the conventional therapy patients $(29.1 \%$ versus $22.4 \%, P<0.05)$. In addition, intensive insulin therapy was associated with a significantly lower infection rate and shorter ICU stay. However, the incidence of severe hypoglycemia in the tight glucose control group was not reported.

Most of the other clinical studies of patients with TBI, as well as stroke and subarachnoid hemorrhage, have not found benefit from tight glucose control, and there is increasing concern about the associated risk of hypoglycemic episodes and the further neuronal injury that can result from hypoglycemia $[10,14,15]$. Episodes of hypoglycemia have been found to be associated with increased extracellular levels of glutamate, glycerol, and the lactate/ pyruvate ratio, all measures of cellular distress [16]. In one prospective observational study of 30 ICU patients (TBI, stroke, subarachnoid hemorrhage), the safety of continuous insulin infusions for maintaining blood glucose levels between 81 and $110 \mathrm{mg} / \mathrm{dl}$ was studied [17]. Adherence to the protocol was $71 \%$, but blood glucose levels were maintained in the desired range for only $42 \%$ of the total protocol implementation time. Consequently, $60 \%$ of the patients in this study experienced at least one hypoglycemic event. A retrospective comparison of 57 neuro-ICU patients who had tight glucose control with 64 patients admitted to the ICU prior to initiation of the protocol also found a higher incidence of hypoglycemia, as well as a longer ICU stay, in the group with tight glucose control [18]. A prospective study of 97 patients with severe TBI assigned either to a group targeted to blood glucose levels of $80-120 \mathrm{mg} / \mathrm{dl}$ using a continuous insulin infusion, or to a group that received insulin only if the blood glucose levels exceeded $220 \mathrm{mg} / \mathrm{dl}$, also found that episodes of hypoglycemia, defined as a blood glucose $<80 \mathrm{mg} / \mathrm{dl}$, were significantly more common for the tight glucose control group [19]. Although the duration of ICU stay also was shorter for that group, there was no difference in ICU infection rates, or in GOS or mortality at 6 months.

Several investigators used microdialysis to examine the metabolic effects of tight glucose control, with the probes placed either in normal appearing brain, or brain adjacent to contusions. Changes in dialysate levels of glucose, lactate, and pyruvate have been shown to correlate well with glucose metabolism as defined with fluorodeoxyglucose-PET [20]. In 20 patients with severe TBI, continuous insulin infusions were used to maintain blood glucose levels of $80-120 \mathrm{mg} / \mathrm{dl}$ [21]. Patients with dialysate glucose levels $<0.7 \mathrm{mmol} / \mathrm{L}(12.6 \mathrm{mg} / \mathrm{dl})$ and lactate/pyruvate ratios $>40$ were considered in 'brain energy crisis', and this condition was associated with a seven-fold increase in the odds of mortality at hospital discharge. Compared with patients in whom the blood glucose was not tightly controlled (121-180 mg/dl), tight glucose control was associated with a significant increase in the incidence of dialysate glucose levels $<0.7 \mathrm{mmol} / \mathrm{L}$ $(12.6 \mathrm{mg} / \mathrm{dl})$ and lactate/pyruvate ratios $>40$ (brain energy crisis). In similar studies at the University of California, Los Angeles, 14 TBI patients acutely managed with intensive insulin therapy were compared with 33 TBI patients treated with a 'loose insulin protocol' [22]. Intensive insulin therapy resulted in a $70 \%$ reduction of dialysate glucose levels, a significant increase in the lactate/pyruvate ratio, which frequently exceeded 40 , and increased levels of glutamate, another marker of cellular distress following trauma. Significantly, more of the intensive-insulin-therapy patients had critically low extracellular glucose levels compared with those who had the loose insulin protocol. Moreover, the percentage of time that the dialysate lactate/pyruvate ratio was above 40 was significantly correlated with the extent of frontal lobe brain atrophy at 6 months after injury [23]. This was observed even in patients who had had normal appearing 
frontal lobes on their initial CT (computed tomography) scans immediately after injury.

During the acute care of patients with severe TBI, there is some evidence that the optimal blood glucose level may change over time. Meier et al. [24] retrospectively evaluated the influence of predefined blood glucose targets $(63-117 \mathrm{mg} / \mathrm{dl}$ versus $90-144 \mathrm{mg} / \mathrm{dl})$ on intracranial pressure, mortality, and length of stay in the ICU in 228 patients with severe TBI. They found that maintaining the blood glucose at $90-144 \mathrm{mg} / \mathrm{dl}$ was beneficial during the first week after injury primarily because there were significantly fewer hypoglycemic episodes in that group compared to the group for whom $63-117 \mathrm{mg} / \mathrm{dl}$ was the target. During the second week the group maintained at the lower target range had a reduced intracranial pressure, and decreased rates of pneumonia, bacteremia, and urinary tract infections compared to the higher blood glucose group.

\section{Alternative fuels}

Glucose may not be the optimum fuel for the acutely injured brain. While glucose appears to be the primary metabolic substrate in the healthy brain, lactate may be the preferred energy substrate following TBI. In a rodent study of cerebral oxygen consumption following fluid percussion injury, it was found that glucose sustained mitochondrial respiration at a low level 'fixed' rate, but increasing its concentration did not result in upregulation of oxygen consumption [25]. However, lactate administration resulted in a dose-dependent increase in mitochondrial oxygen consumption that may well have enabled the mitochondria to meet the increased energy needs of the injured brain. There also is experimental evidence that astrocytes contain low levels of glycogen, and that during hypoglycemia the astrocyte glycogen breaks down to lactate that is then transferred to adjacent neurons or axons and is used aerobically as fuel [26]. Astrocyte glycogen is thereby thought to offer some protection against hypoglycemic neural injury. Ketones also have been proposed as an alternative fuel following TBI [27]. In a murine study of controlled cortical impact injury, feeding the rat a ketogenic diet after injury led to a more rapid normalization of the cerebral metabolic rate for glucose (CMRglucose), and decreased contusion volume [28].

\section{Implications for clinical practice}

While there is experimental evidence that elevated blood glucose levels can cause or exacerbate secondary brain injury, a critical issue yet to be resolved is that of cause or effect. In one large cohort of severely injured trauma patients, those with early hyperglycemia did have a twofold higher mortality rate and a 30\% higher incidence of multiple organ failure compared to those who did not [29]. Van Beek et al. [30] correlated admission glucose levels to 6-month outcomes in nearly 5,000 patients from six phase III trials entered into the IMPACT (International Mission for Prognosis and Analysis of Clinical Trials in TBI) database, and found a significant association with increasing levels of admission blood glucose and poor outcomes. But in both of these studies, the increased blood glucose levels may have been related to the increased stress response associated with more severe injuries [31]; that is, elevated blood glucose levels were a reflection, but not the cause, of very severe injury. So while it is clear that with TBI, as well as with stroke and a number of other neurologic diseases, hyperglycemia is common soon after the injury, it is not clear that aggressive reduction of the elevated blood glucose will improve neurologic outcomes.

It is increasingly apparent, however, that tight glucose control is not only associated with increased hypoglycemic episodes, but also with direct extracellular (microdialysis) evidence of cellular distress and brain energy crisis. In addition, there is evidence that lactate, the principle metabolite of anaerobic glycolysis, may be a preferred fuel for neurons after TBI. There even is evidence for an increase in brain metabolic demand early after injury that may lead to a deficiency in cerebral extracellular glucose [32].

In conclusion, the majority of currently available clinical and preclinical evidence does not support tight glucose control (maintenance of blood glucose levels below 110$120 \mathrm{mg} / \mathrm{dl}$ ) during the acute care of patients with severe TBI.

\section{Abbreviations}

CMRglucose, cerebral metabolic rate for glucose; CT, computed tomography; GOS, Glasgow Outcome Scale; ICU, intensive care unit; IMPACT, International Mission for Prognosis and Analysis of Clinical Trials in TBI; PET, positron emission tomography; TBI, traumatic brain injury; THAM, tromethamine.

\section{Competing interests}

The author declares that he has no competing interests.

\section{References}

I. Kato T, Nakayama N, Yasokawa Y, Okumura A, Shinoda J, Iwama T: Statistical image analysis of cerebral glucose metabolism in patients with cognitive impairment following diffuse traumatic brain injury. J Neurotrauma 2007, 24:919-26.

2. Nakashima T, Nakayama N, Miwa K, Okumura A, Soeda A, Iwama T: Focal brain glucose hypometabolism in patients with neuropsychologic deficits after diffuse axonal injury. AJNR Am J Neuroradiol 2007, 28:236-42. 
3. Salim A, Hadjizacharia P, Dubose J, Brown C, Inaba K, Chan LS, Margulies D: Persistent hyperglycemia in severe traumatic brain injury: an independent predictor of outcome. Am Surg 2009, 75:25-9.

4. Holbein M, Béchir M, Ludwig S, Sommerfeld J, Cottini SR, Keel M, Stocker R, Stover JF: Differential influence of arterial blood glucose on cerebral metabolism following severe traumatic brain injury. Crit Care 2009, 13:RI3.

FI000 Factor 3.0 Must Read

Evaluated by Arun Gupta 27 Mar 2009

5. Suh SW, Shin BS, Ma H, Van Hoecke M, Brennan AM, Yenari MA, Swanson RA: Glucose and NADPH oxidase drive neuronal superoxide formation in stroke. Ann Neurol 2008, 64:654-63.

6. Suh SW, Gum ET, Hamby AM, Chan PH, Swanson RA: Hypoglycemic neuronal death is triggered by glucose reperfusion and activation of neuronal NADPH oxidase. J Clin Invest 2007, II7:910-8.

FI000 Factor 3.0 Must Read

Evaluated by Kyong Soo Park 23 Jul 2007

7. Tisdall MM, Tachtsidis I, Leung TS, Elwell CE, Smith M: Increase in cerebral aerobic metabolism by normobaric hyperoxia after traumatic brain injury. J Neurosurg 2008, 109:424-32.

8. Hertz L: Bioenergetics of cerebral ischemia: a cellular perspective. Neuropharmacology 2008, 55:289-309.

9. Marmarou A, Holdaway R, Ward ID, Yoshida K, Choi SC, Muizelaar IP, Young HF: Traumatic brain tissue acidosis: experimental and clinical studies. Acta Neurochir Suppl 1993, 57:160-4.

10. Prakash A, Matta BF: Hyperglycaemia and neurological injury. Curr Opin Anaesthesiol 2008, 21:565-9.

II. Wolf AL, Levi L, Marmarou A, Ward JD, Muizelaar PJ, Choi S, Young H, Rigamonti D, Robinson WL: Effect of THAM upon outcome in severe head injury: a randomized prospective clinical trial. J Neurosurg 1993, 78:54-9.

12. Muizelaar JP, Marmarou A, Ward JD, Kontos HA, Choi SC, Becker DP, Gruemer H, Young HF: Adverse effects of prolonged hyperventilation in patients with severe head injury: a randomized clinical trial. J Neurosurg 1991, 75:731-9.

13. Yang $M$, Guo Q, Zhang $X$, Sun S, Wang Y, Zhao L, Hu E, Li C: Intensive insulin therapy on infection rate, days in NICU, inhospital mortality and neurological outcome in severe traumatic brain injury patients: A randomized controlled trial. Int J Nurs Stud 2009, 46:753-8.

14. Vespa PM: Intensive glycemic control in traumatic brain injury: what is the ideal glucose range? Crit Care 2008, I 2: I75.

15. Bruno A, Kent TA, Coull BM, Shankar RR, Saha C, Becker KJ, Kissela BM, Williams LS: Treatment of hyperglycemia in ischemic stroke (THIS): a randomized pilot trial. Stroke 2008, 39:384-9.

16. Schlenk F, Nagel A, Graetz D, Sarrafzadeh AS: Hyperglycemia and cerebral glucose in aneurysmal subarachnoid hemorrhage. Intensive Care Med 2008, 34:1200-7.

FI000 Factor 6.4 Must Read

Evaluated by Takefumi Sakabe 3I Jul 2008, Martin Smith 20 Aug 2008

17. Oeyen SG, Hoste EA, Roosens CD, Decruyenaere JM, Blot SI: Adherence to and efficacy and safety of an insulin protocol in the critically ill: a prospective observational study. $\mathrm{Am}$ J Crit Care 2007, 16:599-608.

18. Wittenberg MD, Gattas DJ, Ryan A, Totaro R: Introduction of intensive glycaemic control into a neurosurgical intensive care unit: a retrospective cohort study. Crit Care Resusc 2008, 10:203-8.

19. Bilotta F, Caramia R, Cernak I, Paoloni FP, Doronzio A, Cuzzone V, Santoro A, Rosa G: Intensive insulin therapy after severe traumatic brain injury: a randomized clinical trial. Neurocrit Care 2008, 9:159-66.

Changes Clinical Practice

FI000 Factor 6.4 Must Read

Evaluated by Elfyn Thomas 06 Nov 2008, Martin Smith 16 Dec 2008

20. Hutchinson PJ, O'Connell MT, Seal A, Nortje J, Timofeev I, AI-Rawi PG, Coles JP, Fryer TD, Menon DK, Pickard JD, Carpenter KL: A combined microdialysis and FDG-PET study of glucose metabolism in head injury. Acta Neurochir 2009, I I I:5 I-6I; discussion 6I.

21. Oddo M, Schmidt JM, Carrera E, Badjatia N, Connolly ES, Presciutti M, Ostapkovich ND, Levine JM, Le Roux P, Mayer SA: Impact of tight glycemic control on cerebral glucose metabolism after severe brain injury: a microdialysis study. Crit Care Med 2008, 36:3233-8

Changes Clinical Practice

FI000 Factor 6.7 Must Read

Evaluated by Donald Marion 23 Dec 2008, Salvatore M Maggiore 05 Jan 2009, Daniel Hanley 12 Mar 2009, Luzius A Steiner 24 Apr 2009

22. Vespa P, Boonyaputthikul R, McArthur DL, Miller C, Etchepare M, Bergsneider M, Glenn T, Martin N, Hovda D: Intensive insulin therapy reduces microdialysis glucose values without altering glucose utilization or improving the lactate/pyruvate ratio after traumatic brain injury. Crit Care Med 2006, 34:850-6.

Changes Clinical Practice

FI000 Factor 6.5 Must Read

Evaluated by Martin Smith 20 Mar 2006, Joseph Carcillo 07 Dec 2007, Mark Nunnally 20 Jan 2009

23. Marcoux J, McArthur DA, Miller C, Glenn TC, Villablanca P, Martin NA, Hovda DA, Alger JR, Vespa PM: Persistent metabolic crisis as measured by elevated cerebral microdialysis lactatepyruvate ratio predicts chronic frontal lobe brain atrophy after traumatic brain injury. Crit Care Med 2008, 36:287I-7.

FI000 Factor 3.0 Must Read Evaluated by Arun Gupta 08 Oct 2008

24. Meier R, Béchir M, Ludwig S, Sommerfeld J, Keel M, Steiger P, Stocker R, Stover JF: Differential temporal profile of lowered blood glucose levels ( 3.5 to $6.5 \mathrm{mmol} / \mathrm{l}$ versus 5 to $8 \mathrm{mmol} / \mathrm{l}$ ) in patients with severe traumatic brain injury. Crit Care 2008, 12:R98.

25. Levasseur JE, Alessandri B, Reinert M, Clausen T, Zhou Z, Altememi N, Bullock MR: Lactate, not glucose, up-regulates mitochondrial oxygen consumption both in sham and lateral fluid perfussed rat brains. Neurosurgery 2006, 59: I I22-30; discussion II30-I.

26. Brown AM, Ransom BR: Astrocyte glycogen and brain energy metabolism. Glia 2007, 55: I263-71.

27. Prins M: Diet, ketones, and neurotrauma. Epilepsia 2008, 49(Suppl 8): III-3.

28. Prins $M$, Hovda $D$ : The effects of age and ketogenic diet on local cerebral metabolic rates of glucose after controlled cortical impact injury in rats.J Neurotrauma 2009, Feb I8. [Epub ahead of print].

29. Sperry JL, Frankel HL, Vanek SL, Nathens AB, Moore EE, Maier RV, Minei JP: Early hyperglycemia predicts multiple organ failure and mortality but not infection. J Trauma 2007, 63:487-93; discussion 493-4.

30. Van Beek JG, Mushkudiani NA, Steyerberg EW, Butcher I, McHugh GS, Lu J, Marmarou A, Murray GD, Maas Al: Prognostic value of admission laboratory parameters in traumatic brain injury: results from the IMPACT study. J Neurotrauma 2007, 24:315-28.

3I. Schirmer-Mikalsen K, Vik A, Gisvold SE, Skandsen T, Hynne H, Klepstad P: Severe head injury: control of physiological variables, organ failure and complications in the intensive care unit. Acta Anaesthesiol Scand 2007, 5 I: I 194-20I.

32. Oddo M, Schmidt JM, Mayer SA, Chiolero RL: Glucose control after severe brain injury. Curr Opin Clin Nutr Metab Care 2008, I I:I34-9. 